\title{
Regions, concepts and integrations
}

\author{
Henk ten Have $\cdot$ Bert Gordijn
}

Published online: 26 September 2012

(C) Springer Science+Business Media Dordrecht 2012

This summer the Cleveland Clinic announced that their staff had been reinforced with a 'regional bioethicist'. Initially, we were assuming that this might indicate a new specialized sub-discipline within bioethics, adding to the already burgeoning assortment of specific expert fields such as global ethics, genethics, nanoethics, neuroethics and so forth. But we were wrong: the regional bioethicist turns out to be a bioethicist with a pager available for the geographical area around Cleveland. Be that as it may, in the current issue of the journal, the idea of region is pivotal.

The thematic section, edited by Ana Borovecki, is focused on Mediterranean Bioethics. Although the section includes very interesting articles, it presents a controversial concept, for at least two reasons. First, it is not clear whether, and if yes, to what extent we can talk here of a separate bioethics that is different, for example, from Latin-American or African bioethics. The word 'Mediterranean Bioethics' refers to a 'regional bioethics', which seems reasonable as long as it refers to a geographical area within which bioethics is developed and practiced. If it is argued that it is a substantially different ethics, however, the idea becomes more convoluted. Second, the concept is problematic since it is not clear what the Mediterranean region exactly is. Former French president Sarkozy proposed to establish a Mediterranean Union. Due to opposition from many European Union member states, Sarkozy had to change his plans, and with his typical political versatility it was now baptized the 'Union for the Mediterranean'. The Union was officially launched in 2008 and is headquartered in Barcelona with 43 member countries. Although the term 'Mediterranean' usually refers to the sea

H. ten Have $(\bowtie) \cdot$ B. Gordijn

Pittsburgh, PA, USA

e-mail: tenhaveh@duq.edu enclosed by three continents, countries like Portugal and Macedonia are not bordering this sea but still regarded as 'Mediterranean'.

Another example of a regional approach in this issue is the article on bioethics in Belarus (Vishneuskaya 2012). The author describes how bioethics was necessary in a country with a unique political and social context, characterized by an authoritarian system, public mistrust, and ingrained medical paternalism, reflecting a "former Soviet Union mentality" that in daily life however might not be so 'former'. Bioethics as a discourse that is emphasizing individual freedom and human rights might demonstrate at least in the context of medicine and healthcare how to cope with social and technological changes. A small group of committed and very energetic scholars have produced in a rather short time impressive results. Having visited Minsk several times, we both could observe their enthusiasm, particularly in teaching ethics to a new generation of professionals.

\section{Conceptual analysis}

Furthermore interesting in this issue are various efforts to go beyond 'regional approaches'. Advances in philosophy of medicine, healthcare and bioethics can only be made, if concepts are used in as clear a manner as possible. Conceptual analysis is the contribution par excellence that philosophers can make to intellectual progress. Whatever our field of study or our area of work, it should be clear what we are talking about. This issue features several examples of such conceptual analysis.

One example is Göran Hermerén's contribution (2012). For a long time he has served as President of the European Group on Ethics of Science and New Technologies (EGE) 
in Brussels. Under his guidance EGE has produced many interesting and robust recommendations to the European Commission. In its reports the EGE frequently resorted to the principle of proportionality arguing that there should be an adequate balance between ends and means in assessing the impact of innovations and new technologies. As an abstract painter Hermerén proceeds to dissect and analyze this principle. Thus, he shows how it can be revised and refined to make it better applicable. Analyzing the concept of autonomy is a daunting task but it has not prevented Greaney et al. (2012) to undertake it in connection to the growing availability of self-testing diagnostic devices. The authors not only deconstruct the notion as commonly used in bioethical discourse but they also provide a constructive account how the notion of autonomy should be used in a context of professional responsibility, care and solidarity. A final example of conceptual analysis is provided in the contribution on compassion. The author, Gelhaus (2012b), with her background in medicine as well as philosophy has written a triptych addressing the question what should be the proper professional attitude of physicians. The first article, on empathy, has been published earlier (Gelhaus 2012a), and the third one, on care, will be published in one of the future issues of the journal.

\section{An integrative approach}

Clarification of concepts is not the only prerequisite of intellectual advances. What is also necessary is to bring disparate information together in a coherent framework, so that knowledge becomes understandable and useful to comprehend the present state of the art in our area of scholarly work. Integration is possible because, as the French philosopher Edgar Morin has called it, concepts are travelling, they migrate from one field to another, and this migration makes disciplines flourishing (Morin 2005). An integrative approach is characteristic for contemporary bioethics. It is a methodological requirement to overcome narrow-minded, regional efforts. The inventor of the term 'bioethics' himself, Van Rensselaer Potter, strongly argued that in order to cope with the basic problems of humankind we need a new science combining knowledge from the sciences, especially modern biology, and from the humanities, especially ethics and philosophy (ten Have 2012). Contemporary bioethics therefore can only be interdisciplinary and integrative. Vishneuskaya (2012) rightly points out that the trend towards integration of science and humanities is typical for the bioethical approach in Belarus. In fact, however, this is typical for bioethics everywhere.

However, an integrative approach can take a more political turn. It is taken hostage in a dispute about who exactly invented the term 'bioethics'. Connected with the claim that it was in fact the German pastor Fritz Jahr who first used the term in the 1920s is the statement that he was the first to develop an integrative model of ethics (Muzur and Sass 2012). These claims of course need further analysis and criticism. Jahr's view seems to provoke an 'implosion' of bioethics, stretching bioethics so widely, covering all forms of life, and including spiritual and unseen worlds that it becomes a 'theory of everything'. But the claim about the German coinage of 'bioethics' is not just historical; it is also connected with a particular regional approach to bioethics. Integrative bioethics is now the dominating ethics in Croatia. It is labeled the "Zagreb mantra" (Bracanovic 2012, p. 1). Currently, one can hardly become a respectable academic bioethicist in Croatia, according to Bracanovic, if one does not adhere to this mantra. The methodological requirement of integration needs to go beyond regional approaches in bioethics and should open up new fields of research. It is not an instrument to promote a particular school of bioethics or another regional approach.

\section{References}

Bracanovic, Tomislav. 2012. From integrative bioethics to pseudoscience. Bioethics. doi:10.1111/j.1471-8847.2012.00330.x.

Gelhaus, Petra. 2012a. The desired moral attitude of the physician: (I) empathy. Medicine, Health Care and Philosophy 15(2): 103-113.

Gelhaus, Petra. 2012. The desired moral attitude of the physician: (II) compassion. Medicine, Health Care and Philosophy, this issue.

Greaney, Anna-Marie, O’Mathúna, Dónal P. and Scott, P. Anne. 2012. Patient autonomy and choice in healthcare: self-testing devices as a case in point. Medicine, Health Care and Philosophy, this issue.

Hermerén, Göran. 2012. The principle of proportionality revisited: interpretations and applications. Medicine, Health Care and Philosophy, this issue.

Morin, Edgar. 2005. Introduction à la pensée complexe. Paris: Editions du Seuil.

Muzur, Amir, and Hans-Martin Sass. 2012. Fritz Jahr and the foundations of global bioethics. LIT Verlag: The Future of Integrative Bioethics. Vienna/Berlin.

ten Have, Henk. 2012. Potter's notion of bioethics. Kennedy Institute of Ethics Journal 22(1): 59-82.

Vishneuskaya, Yuliya A. 2012. Analysis and critical review of the development of bioethics in Belarus. Medicine, Health Care and Philosophy, this issue. 